\title{
Adherence to Benzathine Penicillin G Secondary Prophylaxis and Its Determinants in Patients with Rheumatic Heart Disease at a Cardiac Center of an Ethiopian Tertiary Care Teaching Hospital
}

This article was published in the following Dove Press journal:

Patient Preference and Adherence

Kajela Kibirat Mekonen

Malede Berihun Yismaw $\mathbb{D}$

Alfoalem Araba Abiye $(\mathbb{D}$

Tamrat Assefa Tadesse (D)

Department of Pharmacology and Clinical Pharmacy, School of Pharmacy, College of Health Sciences, Addis Ababa University, Addis Ababa, Ethiopia
Correspondence: Tamrat Assefa Tadesse P.O. Box: 9086, Addis Ababa, Ethiopia Email tamrat.assefa@aau.edu.et
Purpose: Benzathine penicillin G (BPG) monthly administration is the most effective method for secondary prophylaxis against acute rheumatic fever (ARF). BPG's efficacy largely depends on adherence to treatment. This study was aimed at assessing adherence to BPG prophylaxis and its determinants among adult patients with rheumatic heart disease.

Patients and Methods: An institutional cross-sectional study design was used. One hundred and forty-five patients receiving monthly BPG at the Adult Cardiac Clinic of Tikur Anbessa Specialized Hospital (TASH) were interviewed. Their 1-year BPG prophylaxis administration record was also reviewed. The rate of adherence to BPG injection was determined by calculating the percentage of the administered drug from the total expected doses. Data were entered and analyzed using Statistical Package for Social Sciences (SPSS) software version 25. Both descriptive and logistic regression analyses were computed to describe different variables and assess factors associated with adherence, respectively. A p-value $<0.05$ was used to declare association.

Results: Among a total of 145 study participants involved, the majority (76.6\%) of them had been receiving BPG for the last 10 years. The average adherence rate to monthly BPG injection was $80.60 \%$ with a range of $0 \%$ to $100 \%$. However, only $101(69.7 \%$ ) of participants were taking $\geq 80 \%$ of their prescribed monthly BPG prophylaxis doses. Study participants with informal education $1.10(0.023-46.96)$ and secondary school education $0.89(0.10-8.11)$ were more and less likely to adhere to BPG injection, respectively, when compared with those who attended higher education programs. The regression analysis showed patients who were not admitted to the hospital (AOR: 26.22; CI: 2.55-269.70; $\mathrm{p}=0.006$ ) and once admitted patients (AOR: 50.08; CI: 2.87-873.77; $\mathrm{p}=0.007$ ) were more likely to adhere to their BPG injections than those admitted twice or more. The study participants who waited until the next appointment were also less adherent (AOR: 0.02; CI: $0.00-0.13 ; \mathrm{p}=0.000$ ) than those who went a few days later for receiving the missed/late dose. Conclusion: The adherence rate to BPG injection among RHD patients was found to be high (80.60\%). Patients' admission status and their action on missed and/or late doses were found to be important determinants of adherence in this study.

Keywords: rheumatic heart disease, benzathine penicillin G, adherence rate, Tikur Anbessa Specialized Hospital, Ethiopia

\section{Introduction}

Acute rheumatic fever (ARF) is a nonsuppurative complication of pharyngeal infection with group A Streptococcus (GAS). The clinical presentation includes 
arthritis, carditis, chorea, subcutaneous nodules, and erythema marginatum. It is frequently associated with significant heart valve damage, which is termed as rheumatic heart disease (RHD). ${ }^{1}$

The burden of ARF and RHD are major public health problems in low-income countries. ${ }^{2}$ The prevalence of RHD appears to be increasing worldwide and it remains a significant cause of cardiovascular morbidity and mortality. ${ }^{3}$ In high-income countries, RHDs have been eliminated and are not public health problems, while it continues to cause significant morbidity and premature mortality in low-income settings ${ }^{4}$ as overcrowding and low socio-economic status are the known risk factors for the occurrence ARF. ${ }^{5}$ A population-based study in the rural part of Ethiopia reported an overall prevalence of 37.5 RHD cases per 1000 population and its prevalence increased to 60 cases per 1000 in those aged 16-20 years. ${ }^{6}$

Several strategies have been implemented for rheumatic fever and RHD control. These include primary, primordial and secondary prevention. ${ }^{7}$ Though primary preventions of ARF in those individuals at risk of developing the disease condition is considered a cornerstone in the management of RHD, ${ }^{1}$ secondary prevention remains the widely practiced management approach in the care of individuals once they developed RHD. ${ }^{8,9}$ Benzathine penicillin G (BPG) secondary antibiotic prophylaxis (SAP) has been shown to reduce the risk of ARF recurrences and the development or worsening of RHD with well-established effectiveness. ${ }^{9,10}$ As a result, long-term BPG treatment is recommended to prevent GAS reinfection and reduce the morbidity and mortality associated with both recurrent ARF and RHD. ${ }^{11,12}$ BPG prophylaxis efficacy against ARF largely depends on adherence to treatment. ${ }^{13}$ However, poor adherence to prophylaxis is the major problem in SAP. ${ }^{14}$ Several factors including psychosocial-, demographic-, and medical-related characteristics have been identified as attributes to nonadherence with BPG secondary prophylaxis. ${ }^{15,16}$ In Ethiopia, RHD is one of the major health problems resulting in significant morbidity and mortality. ${ }^{16-19}$ From our healthcare experiences, there were concerns on adherence to monthly BPG prophylaxis. Despite such experience, there was a scarcity of local evidence. This study was, therefore, conducted to bridge the gap. It can be used as a preliminary data on BPG prophylaxis in patients with RHD. This, in turn, supports quality improvement service on adherence to monthly BPG administration which may improve RHD patients' health-related quality of life and treatment outcomes. Also, findings and recommendations obtained from this study might help to influence the development of guidelines and policies to optimize the monthly administration of BPG in patients with rheumatic heart diseases. Therefore, this study seeks to evaluate the rate of adherence to monthly BPG injection and its determinant factors in patients attending Tikur Anbessa Specialized Hospital (TASH) Cardiac Clinic, Addis Ababa, Ethiopia.

\section{Materials and Methods Study Setting}

This study was conducted at TASH, Addis Ababa, Ethiopia. It is one of the largest specialized teaching hospitals in the country. The hospital has around 700 beds and serves more than half a million patients per annum in its outpatient, inpatient and emergency departments. Adult Cardiac Clinic is one the outpatient clinic which gives service for patients having cardiovascular disorders including RHD.

\section{Study Design and Study Period}

A cross-sectional study design that involved interviewing patients and reviewing their BPG prophylaxis injection follow-up records was conducted in the studied hospital. One-year records (April 1, 2018 to March 31, 2019) of BPG administration was reviewed for all interviewed patients. This period was selected to get the earliest records with better information in terms of quality and completeness. We reviewed the immediate 1 -year records preceding interview data collection period. This, in turn, supported us to align data from interview with review records easily.

\section{Eligibility Criteria}

All patients with RHD and visiting the cardiac clinic of the hospital during study period and patients who had been receiving BPG prophylaxis at least for 6 months were included in our study. However, physically ill patients, those unable to answer questions, refuse to give consent both for interview and review of their monthly BPG prophylaxis injection follow-up records, discontinued BPG by physician order, and patients with incomplete BPG injection follow-up records were excluded from the study.

\section{Sample Size}

The study included all eligible patients who met the inclusion criteria. A convenient sampling method was employed as sampling techniques and all study participants available 
during the study period were included in the study. Accordingly, a total of 145 patients were included in the final analysis.

\section{Study Variables}

Adherence to BPG prophylaxis was considered as dependent variable while age, sex, marital status, religion, education level, economic and employment status, place of residence and family monthly income, duration of disease since diagnosis, hospitalization, comorbidities, duration on $\mathrm{BPG}$, site of BPG injection, side effects related to BPG, missed and late doses of BPG, reasons for missed and late dose were considered as independent variables.

\section{Data Collection and Management}

Interview data were collected using a pretested questionnaire. Data abstraction format was used to extract data from patients' records. The collected data include all pertinent information on the socio-demographic and clinical characteristics of the study participants. The data collection instrument was developed from different literatures and modified based on the local context and patients understanding. It was validated by a senior cardiologist and clinical pharmacist before use. The rate of adherence to monthly BPG injection was determined by calculating the percentage of administered doses based on the following formula. ${ }^{20}$

$$
\text { Adherenence rate }=\frac{\begin{array}{l}
\text { Number of BPG doses actually administered } \\
\text { to specific patient }
\end{array}}{\begin{array}{l}
\text { Number of BPG doses expected for that } \\
\text { specific patient }
\end{array}} \times 100 \%
$$

The data were collected by fifth year undergraduate pharmacy students of Addis Ababa University, School of Pharmacy. Half-day training was given for the data collectors on how to approach study participants and on how to extract the required information from patients and their charts. The questionnaires were prepared in English and translated into Amharic and then retranslated to English to maintain consistency. The Amharic version was used for interviewing patients. Data collection tools were pretested in $5 \%$ of the study participants and all necessary amendments were made before using it for data collection.

The collected data were then entered and analyzed using Statistical Package for Social Sciences (SPSS) software version 25. Descriptive statistics including frequency, percentage, mean, and standard deviation was used to present the data. Binary logistic regression analysis was used to identify the determinants of adherence. Variables with $\mathrm{p}<0.25$ in univariate analysis were further analyzed by multiple logistic regressions to avoid confounders. A p-value $<0.05$ was used to confirm an association.

\section{Operational Definition of Outcome Variable}

Adherence to Monthly BPG

Patients were considered as adherent and non-adherent to monthly BPG prophylaxis if they received $\geq 80 \%$; and $<80 \%$ of their monthly prescribed doses of BPG in the last 1 year, respectively. ${ }^{19}$

\section{Ethical Consideration}

Ethical approval was obtained from Addis Ababa University College of Health Science, School of Pharmacy, Ethical Review Board with Ref. No: ERB/SOP/69/04/2019. Permission was also secured from the TASH outpatient department. As per our ethical review board, verbal consent was acceptable and thus approved per the protocol. Besides, informed consent was obtained from each participant and confidentiality was ensured by omitting patient identifiers and giving code number. For study participants under the age of 18 years, parental/guardian informed consent was obtained.

\section{Results}

\section{Socio-Demographics Characteristics}

Of 145 study participants included in the study, majority $(75.9 \%)$ of them were females and the mean age of the participants was $30.12 \pm 9.62$ with a range of $14-58$ years. The number of patients who were single and married constituted $46.9 \%$ each. More than half $(56.6 \%)$ of participants cover their healthcare expenses by themselves (Table 1). Regarding monthly income, about one fourth of them had income of less than 1000 Ethiopian Birr (ETB) per month. Forty-two (29\%) study participants did not have any source of income and depend on others for living.

\section{Clinical Characteristics of Study Participants}

Most $(67.6 \%)$ of the participants were diagnosed with RHD within the last 10 years with the mean years of $9.72 \pm 8.0$. These patients were also diagnosed with multiple co-morbid conditions (Table 2).

Fifty-four $(37.2 \%)$ of participants were admitted to hospital in their last year follow-up period at least once for the problem associated with cardiovascular illness with a mean of $0.59 \pm 0.98$. 
Table I Socio-Demographic Characteristics of Study Participants Receiving BPG, TikurAnbessa Specialized Hospital $(\mathrm{N}=\mid 45)$

\begin{tabular}{|c|c|c|}
\hline \multicolumn{2}{|l|}{ Variables } & \multirow{2}{*}{$\begin{array}{l}\mathbf{N}(\%) \\
35(24.1) \\
110(75.9)\end{array}$} \\
\hline Sex & $\begin{array}{l}\text { Male } \\
\text { Female }\end{array}$ & \\
\hline Age in years & $\begin{array}{l}14-28 \\
29-58\end{array}$ & $\begin{array}{l}73(50.3) \\
72(49.7)\end{array}$ \\
\hline Marital status & $\begin{array}{l}\text { Single } \\
\text { Married } \\
\text { Divorced } \\
\text { Widowed }\end{array}$ & $\begin{array}{l}68(46.9) \\
68(46.9) \\
7(4.8) \\
2(1.4)\end{array}$ \\
\hline Education status & $\begin{array}{l}\text { Unable to write and read } \\
\text { Able to write and read } \\
\text { Primary school (grade 1-8) } \\
\text { Secondary school (grade 9-12) } \\
\text { Certificate/diploma } \\
\text { Degree and above }\end{array}$ & $\begin{array}{l}11(7.6) \\
2(1.4) \\
59(40.7) \\
47(32.4) \\
18(12.4) \\
8(5.5)\end{array}$ \\
\hline Place of residence & $\begin{array}{l}\text { Addis Ababa } \\
\text { Outside of Addis Ababa }\end{array}$ & $\begin{array}{l}84(57.9) \\
61(42.1)\end{array}$ \\
\hline Religion & $\begin{array}{l}\text { Orthodox } \\
\text { Muslim } \\
\text { Protestant }\end{array}$ & $\begin{array}{l}99(68.3) \\
28(19.3) \\
18(12.4)\end{array}$ \\
\hline Employment status & $\begin{array}{l}\text { Employed } \\
\text { Housewife } \\
\text { Farmer } \\
\text { Merchant (Self-employed) } \\
\text { Student } \\
\text { Not working }\end{array}$ & $\begin{array}{l}31(21.4) \\
24(16.6) \\
3(2.1) \\
22(15.2) \\
23(15.9) \\
42(29)\end{array}$ \\
\hline With whom do you live & $\begin{array}{l}\text { Family } \\
\text { Alone }\end{array}$ & $\begin{array}{l}134(92.4) \\
11(7.6)\end{array}$ \\
\hline Family size in numbers & $\begin{array}{l}1-4 \\
5-8 \\
9-13\end{array}$ & $\begin{array}{l}76(52.4) \\
63(43.4) \\
6(4.2)\end{array}$ \\
\hline Monthly income (in Birr) & $\begin{array}{l}<1000 \\
100 \mathrm{I}-3000 \\
300 \mathrm{I}-5000 \\
>500 \mathrm{I} \\
\text { No income }\end{array}$ & $\begin{array}{l}33(22.8) \\
35(24.1) \\
20(13.8) \\
15(10.3) \\
42(29.0)\end{array}$ \\
\hline $\begin{array}{l}\text { How do you get the } \\
\text { medicine? }\end{array}$ & $\begin{array}{l}\text { Cash } \\
\text { Free }\end{array}$ & $\begin{array}{l}82(56.6) \\
62(42.8)\end{array}$ \\
\hline
\end{tabular}

\section{Benzathine Penicillin G-Related \\ Characteristics}

The majority (76.6\%) of study participants had been receiving BPG for the last 10 years with the mean years of $7.0 \pm$ 6.3. The average number of drugs taken by study participants including BPG was $3.43 \pm 1.35$. Regarding knowledge on the purpose of receiving BPG, $48.3 \%$ of the respondents do not know why they were receiving it. It took less than 20 mins for
Table 2 Clinical Characteristics of the Patients with RHD Receiving BPG Prophylaxis, Tikur Anbessa Specialized Hospital ( $N=145)$

\begin{tabular}{|l|l|l|}
\hline \multicolumn{2}{|l|}{ Variables } & $\mathbf{N}(\%)$ \\
\hline $\begin{array}{l}\text { Duration since diagnosis of RHD in } \\
\text { years }\end{array}$ & $\leq 10$ & $98(67.6)$ \\
& $1 \mathrm{I}-20$ & $30(20.7)$ \\
& $2 \mathrm{I}-33$ & $13(9.0)$ \\
& Do not know & $4(2.7)$ \\
\hline $\begin{array}{l}\text { Number of admissions to hospital in } \\
\text { the last I year }\end{array}$ & No & $91(62.8)$ \\
& admission & \\
& Once & $35(24.1)$ \\
& Twice & $12(8.3)$ \\
& Three times & $1(0.7)$ \\
& Four times & $6(4.1)$ \\
\hline Co-morbidities & Hypertension & $7(4.8)$ \\
& Heart failure & $15(10.3)$ \\
& Stroke & $4(2.8)$ \\
& Atrial & $35(24.1)$ \\
& fibrillation & \\
& Gastric & $21(14.5)$ \\
& illness & \\
& Renal disease & $7(4.8)$ \\
& Diabetes & $2(1.4)$ \\
& mellitus & \\
\hline
\end{tabular}

about half (49\%) of study participants to go to the health facility for taking their monthly BPG. The majority of study participants $(62.1 \%)$ waited less than 20 mins at the health facility for administration of BPG. Slightly higher than half $(55.2 \%)$ and about a quarter $(24.8 \%)$ of the respondents complained of injection site pain and twitching/muscle spasm after injection of BPG, respectively (Table 3).

\section{Monthly Benzathine Penicillin G Receiving Practice Among Study Participants}

During the study period, a total of 1170 doses of BPG were expected to be taken by study participants. Nevertheless, 943 doses of BPG were received whereas 227 doses missed. Of the 943 doses received, 291 were lately taken. In this study, $65(44.82 \%)$ of patients missed at least one dose of monthly BPG injection. Table 4 shows the number of patients with their expected, received, missed, late doses of BPG, and uncovered days with means of $8.0 \pm 2.81,1.57 \pm 2.41,6.50$ $\pm 2.92,2.01 \pm 2.82$ and $46.90 \pm 67.61$, respectively.

\section{Reasons for Missed and/or Late Doses of BPG}

The main reason for missing monthly BPG prophylaxis and/or receiving it lately by respondents was forgetting to 
Table 3 BPG-Related Factors in Patients with RHD at Tikur Anbessa Specialized Hospital Addis Ababa, Ethiopia, 2019 (N= I45)

\begin{tabular}{|c|c|c|}
\hline \multicolumn{2}{|l|}{ Variables } & \multirow{2}{*}{$\begin{array}{l}\mathbf{N}(\%) \\
111(76.6) \\
17(11.7) \\
8(5.5) \\
9(6.2)\end{array}$} \\
\hline $\begin{array}{l}\text { Duration since start of receiving BPG } \\
\text { prophylaxis in years }\end{array}$ & $\begin{array}{l}\leq 10 \\
11-20 \\
21-33 \\
\text { Do not know }\end{array}$ & \\
\hline How many drug(s) are you receiving? & $\begin{array}{l}\text { One (only BPG) } \\
\text { Two } \\
\text { Three } \\
\text { Four } \\
\text { Five and above }\end{array}$ & $\begin{array}{l}14(9.7) \\
23(15.9) \\
33(22.8) \\
47(32.4) \\
28(19.3)\end{array}$ \\
\hline Where did you take BPG injection? & $\begin{array}{l}\text { Health center/hospital } \\
\text { Private clinic/hospital } \\
\text { At home }\end{array}$ & $\begin{array}{l}76(52.4) \\
67(46.2) \\
2(1.4)\end{array}$ \\
\hline $\begin{array}{l}\text { In the last } 6 \text { months, in how many } \\
\text { healthcare facilities have you got BPG } \\
\text { injection? }\end{array}$ & $\begin{array}{l}\text { One } \\
\text { Two } \\
\text { More than two } \\
\text { At home }\end{array}$ & $\begin{array}{l}106(73.1) \\
29(20) \\
8(5.5) \\
2(1.4)\end{array}$ \\
\hline $\begin{array}{l}\text { Transportation used for going to facility } \\
\text { for BPG injection }\end{array}$ & $\begin{array}{l}\text { Taxi/bus } \\
\text { Private car } \\
\text { By walking }\end{array}$ & $\begin{array}{l}63(43.4) \\
2(1.4) \\
80(55.2)\end{array}$ \\
\hline $\begin{array}{l}\text { How long does it take to get to health } \\
\text { facility for monthly BPG injection }\end{array}$ & $\begin{array}{l}\text { Less than } 20 \text { mins } \\
20-40 \text { mins } \\
>40 \text { mins }-1 \mathrm{hr} \\
>1-2 \mathrm{hrs} \\
>2 \mathrm{hrs}\end{array}$ & $\begin{array}{l}71(49.0) \\
53(36.6) \\
8(5.5) \\
7(4.8) \\
6(4.1)\end{array}$ \\
\hline $\begin{array}{l}\text { Average waiting time for administration } \\
\text { of } B P G \text { at health facility }\end{array}$ & $\begin{array}{l}<20 \text { mins } \\
20-40 \text { mins } \\
41 \text { min- } 1 \text { hour } \\
>1-2 \text { hrs }\end{array}$ & $\begin{array}{l}90(62.1) \\
38(26.2) \\
14(9.6) \\
3(2.1)\end{array}$ \\
\hline $\begin{array}{l}\text { Experienced side effect related to BPG } \\
\text { in recent administration(s) }\end{array}$ & $\begin{array}{l}\text { Twitching or muscle } \\
\text { spasm } \\
\text { Skin rash around } \\
\text { injection site } \\
\text { Fever } \\
\text { Pain at injection site }\end{array}$ & $\begin{array}{l}36(24.8) \\
7(4.8) \\
6(4.1) \\
80(55.2)\end{array}$ \\
\hline $\begin{array}{l}\text { Knowledge on purpose of receiving } \\
\text { monthly BPG injection }\end{array}$ & $\begin{array}{l}\text { Yes } \\
\text { No }\end{array}$ & $\begin{array}{l}75(51.7) \\
70(76.6)\end{array}$ \\
\hline
\end{tabular}

Note: NB, for some variables, percentage could not add to 100 .

go to health facility (34.5\%) followed by stock out of BPG injection on scheduled time (15.9\%). Other reasons are depicted in Figure 1.

Patients were also asked to give any concerns related to BPG prophylaxis. Accordingly, around half (50.3\%) of them reported poor availability of the drug followed by the refusal of healthcare professionals to administer the drug at facilities even with complete prescription/order for injection (34.5\%). Fear of side effects (23.4\%), poor availability of water of
Table 4 Practice of Receiving BPG Prophylaxis of Study Participants $(\mathrm{N}=\mid 45)$

\begin{tabular}{|l|l|l|}
\hline \multicolumn{2}{|l|}{ Variables } & N(\%) \\
\hline Number of expected doses per & $6-8$ & $102(70.3)$ \\
patient & $9-11$ & $9(6.2)$ \\
& $12-13$ & $34(23.4)$ \\
\hline Received number of doses per & $1-3$ & $10(6.9)$ \\
patient & $4-6$ & $96(66.92)$ \\
& $7-8$ & $13(9.0)$ \\
& $9-12$ & $12(8.3)$ \\
& 13 & $13(9.0)$ \\
\hline Missed number of doses per & $1-4$ & $48(33.1)$ \\
patient & $5-8$ & $14(9.7)$ \\
& $>9$ & $3(2.1)$ \\
& Never missed & $80(55.2)$ \\
\hline Amount of late doses per patient & $1-4$ & $65(44.8)$ \\
& $5-8$ & $13(9.0)$ \\
& $>9$ & $5(3.4)$ \\
& Never late & $62(42.8)$ \\
\hline Patient action on missed/late dose & Wait until the next & $39(26.9)$ \\
of BPG injection & appointment & $67(46.2)$ \\
patient & Go a few days & $88(60.7)$ \\
& later & $34(23.4)$ \\
& $<28$ & $17(11.7)$ \\
\hline & $29-112$ & $6(4.1)$ \\
\hline & $113-225$ & \\
\hline
\end{tabular}

injection for reconstitution of the BPG (23.4\%), and closure of the syringe during drawing of the suspension from the vial $(6.2 \%)$ were also other experiences mentioned by study participants while receiving BPG monthly.

\section{Adherence Rate to BPG Prophylaxis}

In the present study, the overall adherence rate to monthly BPG injection was $80.6 \%$ with a range of $0-100 \%$. However, only 101 (69.7\%) of participants were taking at least $80 \%$ of their prescribed doses. This infers only $69.7 \%$ of them are adherent. The result showed that one patient was not received the drug at all, $5.5 \%$ of the patients received their half doses, and $80(55.2 \%)$ have never missed their drug as shown in Table 5.

\section{Factors Associated with Adherence Rate of BPG in Study Participants}

On the bivariate logistic regression analysis, only eight variables were eligible $(\mathrm{p}<0.25)$ to be analyzed by 


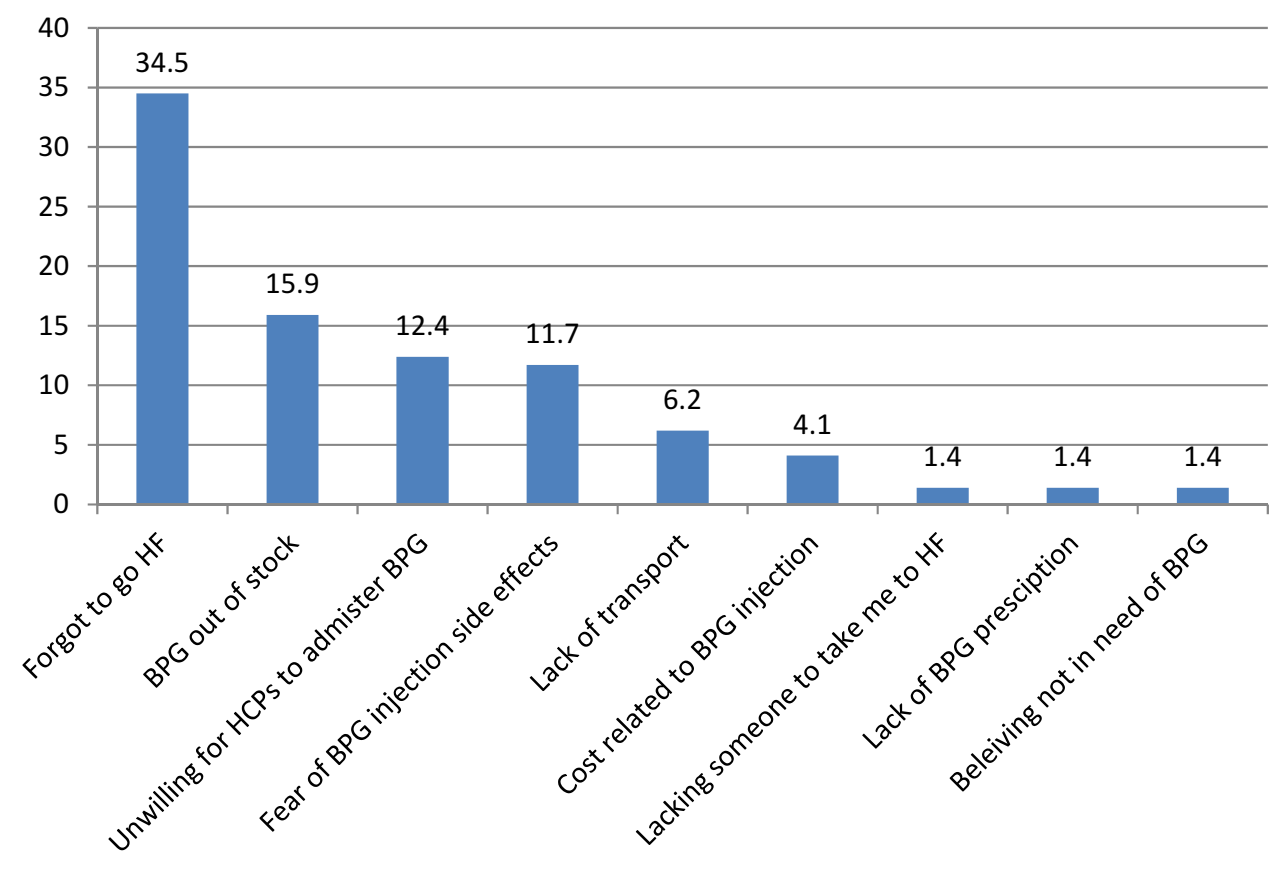

Figure I Reasons for missed and/or late doses of BPG.

Abbreviations: HF, health facility; HCPs, healthcare professionals.

multivariate logistic regression (Table 6). Accordingly, religion, educational level, number of hospital admission, duration on BPG taking, average waiting time for taking BPG at the health facility, knowledge on purpose of receiving BPG, action on missed and/or late dose and reasons for missing/ taking late were eligible for multivariate analysis. Study participants who did not know the indication of BPG were about two times more adherent to their monthly regimen than those who knew the purpose of receiving this drug. The multivariate logistic regression showed that patients who were not admitted to hospital (AOR: 26.22; CI: 2.55269.70; $\mathrm{p}=0.006$ ) and once admitted patients (AOR: 50.08; CI: 2.87-873.77; $\mathrm{p}=0.007)$ are more adherent as compared to subjects admitted twice and above. Moreover, participants who waited until the next appointment are less adherent (AOR: 0.02; CI: 0.00-0.13; $\mathrm{p}=0.000$ ) than those go a few days later for receiving the missed/late dose.

\section{Discussion}

Patients with RHD are expected to receive at least $80 \%$ of the annual prescribed BPG injections to be considered as adherent to the monthly prophylaxis. Receiving less than $80 \%$ of the injections places an individual at a higher risk of recurrent ARF and its complications. ${ }^{13}$ In the current study, an overall adherence rate among the study participants was $80.6 \%$.

The level of adherence determined in the current study was considerably greater than studies conducted in Pakistan $(73.5 \%),{ }^{21}$ Uganda (54\%), ${ }^{13}$ Australia Northern Territory $(63.5 \%),{ }^{4}$ rural Egypt $(65.5 \%)^{22}$ and New Caledonia (46\%). ${ }^{14}$ This might be due to less waiting time at health facilities for taking BPG injection and need of less than 20 mins to go to health facility among our study participants. More importantly, the high adherence rate in our study may be due to the reason that all our study participants had BPG monthly administration follow-up records at their hand. This was used as a reminder to their follow-up schedule.

Table 5 Adherence Rate in Percentage to BPG Prophylaxis Among Patients Attending Cardiac Adult Clinic of TASH (N=|45)

\begin{tabular}{|l|l|l|l|l|l|l|l|l|l|l|}
\hline Adherence rate in \% & 0.00 & 7.69 & 16.67 & 25.00 & 30.0 & 33.33 & 38.46 & 45.45 & 50.00 & 53.85 \\
$\mathrm{~N}(\%)$ & $\mathrm{I}(0.7)$ & $\mathrm{I}(0.7)$ & $\mathrm{I}(0.7)$ & $2(0.4)$ & $\mathrm{I}(0.7)$ & $5(3.4)$ & $2(\mathrm{I} .4)$ & $2(I .4)$ & $8(5.5)$ & $3(2.1)$ \\
Cumulative \% & 0.7 & $\mathrm{I} .4$ & 2.1 & 3.4 & 4.1 & 7.6 & 9.0 & 10.3 & 15.9 & 17.9 \\
Adherence rate in \% & 58.33 & 62.50 & 66.67 & 76.92 & 83.33 & 84.62 & 87.50 & 91.67 & $92.3 \mathrm{I}$ & 100 \\
$\mathrm{~N}(\%)$ & $\mathrm{I}(0.7)$ & $7(4.8)$ & $10(6.9)$ & $2(1.4)$ & $13(9)$ & $2(1.4)$ & $\mathrm{I}(0.7)$ & $\mathrm{I}(0.7)$ & $2(1.4)$ & $80(55.2)$ \\
Cumulative \% & $\mathrm{I} .6$ & 23.4 & 30.3 & 31.7 & 40.7 & 42.1 & 42.8 & 43.4 & 44.8 & 100 \\
\hline
\end{tabular}


Table 6 Factors Associated with Adherence to BPG Secondary Prophylaxis Among Study participants (N=I45)

\begin{tabular}{|c|c|c|c|c|}
\hline \multicolumn{2}{|l|}{ Variables/Item Description } & \multirow{2}{*}{$\begin{array}{l}\text { COR }(95 \% \mathrm{CI}) \\
7.32(0.49-110.06) \\
1.46(0.40-5.36) \\
0.74(0.22-2.50) \\
I\end{array}$} & \multirow{2}{*}{$\begin{array}{l}\text { AOR }(95 \% \text { CI }) \\
1.10(0.023-46.96) \\
2.60(0.17-3.83) \\
0.89(0.10-8.11) \\
I\end{array}$} & \multirow{2}{*}{$\begin{array}{l}\text { p-value } \\
0.961 \\
0.325 \\
0.918\end{array}$} \\
\hline Educational status & $\begin{array}{l}\text { Informal education } \\
\text { Primary school education } \\
\text { Secondary school education } \\
\text { Diploma, degree and above }\end{array}$ & & & \\
\hline Religion & $\begin{array}{l}\text { Orthodox } \\
\text { Muslim } \\
\text { Protestant }\end{array}$ & $\begin{array}{l}0.26(0.05-1.43) \\
0.19(0.03-1.36) \\
1\end{array}$ & $\begin{array}{l}0.02(0.00-1.88) \\
0.03(0.00-4.24) \\
I\end{array}$ & $\begin{array}{l}0.094 \\
0.169\end{array}$ \\
\hline Number of hospital admissions & $\begin{array}{l}\text { Never admitted } \\
\text { Once } \\
\text { Twice and above }\end{array}$ & $\begin{array}{l}5.54(1.75-17.54) \\
5.70(1.47-22.04) \\
1\end{array}$ & $\begin{array}{l}26.22(2.55-269.70) \\
50.08(2.87-873.77) \\
\text { I }\end{array}$ & $\begin{array}{l}0.006 \\
0.007\end{array}$ \\
\hline Duration since started taking BPG & $\begin{array}{l}\leq 10 \text { years } \\
11-20 \text { years } \\
21-33 \text { years }\end{array}$ & $\begin{array}{l}2.37(0.49-11.44) \\
11.17(1.27-97.99) \\
\text { । }\end{array}$ & $\begin{array}{l}2.34(0.20-27.03) \\
15.12(0.60-385-21) \\
I\end{array}$ & $\begin{array}{l}0.496 \\
0.100\end{array}$ \\
\hline Average waiting time for taking BPG at $\mathrm{HF}$ & $\begin{array}{l}<20 \text { mins } \\
20-40 \text { mins } \\
>40 \text { mins }\end{array}$ & $\begin{array}{l}1.21(0.33-4.50) \\
3.92(0.8 I-19.00) \\
I\end{array}$ & $\begin{array}{l}0.20(0.01-3.0) \\
1.68(0.09-29.63) \\
\text { I }\end{array}$ & $\begin{array}{l}0.252 \\
0.723\end{array}$ \\
\hline Knowledge on purpose of receiving BPG & $\begin{array}{l}\text { The patient knows the purpose } \\
\text { The patient did not know the purpose }\end{array}$ & $\begin{array}{l}0.53(0.23-1.22) \\
1\end{array}$ & $\begin{array}{l}0.32(0.04-2.48) \\
\mathrm{I}\end{array}$ & 0.274 \\
\hline Action on missed and or late dose & $\begin{array}{l}\text { Waiting until the next appointment } \\
\text { Go a few days later }\end{array}$ & $0.05(0.02-0.14)$ & $\begin{array}{l}0.02(0.00-0.13) \\
I\end{array}$ & 0.000 \\
\hline Reasons for missing/taking late dose & $\begin{array}{l}\text { Forgetting to go to health facility } \\
\text { Fear of side effect(s) } \\
\text { Unwilling for healthcare professionals } \\
\text { to administer the drug }\end{array}$ & $\begin{array}{l}2.15(0.86-5.35) \\
82.21(9.87-684.35) \\
4.25(1.42-12.67)\end{array}$ & $\begin{array}{l}1.97(0.40-9.67) \\
0.00(0.00-0.00) \\
0.70(-0.12-3.93)\end{array}$ & $\begin{array}{l}0.402 \\
1.000\end{array}$ \\
\hline
\end{tabular}

Another study also showed 55\% adherence rate of secondary prophylaxis to RHD patients ${ }^{16}$ by mentioning lack of money (38\%), far distance from hospital (26\%), fear of medication side effects and painful injection $(23 \%)$, and lack of knowledge about the disease and prevention $(13 \%)$ as reasons for poor adherence which were also realized in our study even if there is variation on the percentages. A very low overall adherence of $6 \%$ was also reported in the South Pacific nation. ${ }^{23}$ Furthermore, different studies reported reasons for poor adherence were lack of money, far distance from hospital, fear of medication side effects and painful injection, lack of awareness of the importance of BPG, and non-availability of BPG. ${ }^{15,24,25}$ On the contrary, the adherence rate of the present study $(80.6 \%)$ was less than that of Indian and New Zealand studies which reported $(89.6 \%)^{26}$ and $(92 \%)^{27}$ respectively. Another prospective study conducted in India also showed the overall adherence rate of $93.6 \%{ }^{24}$
Though our finding revealed an overall adherence of $>80 \%$, only $69.7 \%$ of the subjects were adhered to the monthly BPG prophylaxis, with adherence rates $\geq 80 \%$. To improve adherence among study participants who did not meet the standard, evidences suggested different strategies like availing the medicine for free in the health facilities and enhancing communication with patients on their experience regarding monthly BPG injection. ${ }^{28}$ In addition, creating personal motivation, educating about the benefit of taking the drug and provision of a reminder system for injections leads to positive outcome. ${ }^{8,25}$

In the present study, the multivariate regression analysis showed that patients who never admitted to health facilities (26 times) and once admitted (50 times) were more adherent to their BPG injection as compared to twice and above admitted patients. In contrary, a study conducted in New Caledonia showed no association. ${ }^{14}$ However, study variables like sex, age, marital status, educational level, duration on BPG, average waiting time for taking BPG, 
knowledge on purpose of receiving BPG, reasons for missing/lately taking did not significantly affect adherence status in our study. In contrast to this, a study from Bangladesh reported that duration on BPG taking, age, sex, education and marital status were significantly associated with therapeutic compliance among the patients with RHD. ${ }^{29}$ Furthermore, a study conducted at Fiji (South Pacific) also revealed that age and duration of taking BPG were associated with the status of adherence. ${ }^{30}$ These differences might be due to the relatively small participants number and the difference in socio-demographic characteristics. Regarding the action on missed and/or late doses, our study revealed waiting until the next appointment is found to be determinant for poor adherence. This can be justified as those patients who visit the clinic after a few days later will become more alert since they think that waiting until the next appointment will worsen their disease condition and decided to go to health facility just after days.

The common reasons reported by respondents for missing BPG prophylaxis injections were forgetting to go to health facility $(34.5 \%)$, being out of stock of BPG (15.9\%), unwillingness of healthcare professionals to administer the drug (12.4\%) and fear of side effects (Figure 1). The same reasons were reported by Musoke et al among patients attending cardiac clinics in Uganda. ${ }^{13}$ Besides this, a study in Fiji reported lack of awareness, feeling well, access and transport cost as determinants of missing of BPG doses by recommending reminder strategies, particularly phone-based reminders which were considered helpful by $94 \%$ of participants to improve adherence. $^{23}$

Patients shall be advised about the importance of monthly BPG injection and its adherence. Since there were no many alternative drugs for secondary prevention of ARF, the hospital should always avail BPG. Concerned bodies like regional health bureaus should train and create awareness for healthcare professionals who are involved in administering the drug since there were huge concern/complaint by patients which might affect their adherence to the drug.

Another recommendation from consultation with global experts in RHD on the characteristics of BPG formulations study suggested changing formulations of BPG to improve its adherence. The components of formulation change shall constitute means of decreasing dosing interval, reducing injection site pain, changing in the mechanism of administration from intramuscular to others (e.g. solid monolith), cold chain storage independence and reduction in drug and other indirect costs. ${ }^{31}$
Our study had some limitations. One of the limitations was the study included a small number of participants due to budget and time constraint. The nature of the study (cross-sectional) is weak to see the actual adherence status and to identify determinants. Thirdly, the documentation process is poor which made difficult to extract information on some occasions.

\section{Conclusion}

The overall adherence rate to BPG injection among RHD patients was high. Patients who were not admitted to hospital $(p=0.006)$ and only admitted once $(p=0.007)$ in their previous year of follow-up were significantly adherent to their drug as compared with those who admitted twice and above. Besides, participants who wait until the next appointment time were less adherent $(\mathrm{p}=0000)$ to their BPG injection than those who go a few days later for receiving the missed/late doses.

\section{Abbreviations}

ARF, acute rheumatic fever; BPG, benzathine penicillin G; GAS, group A Streptococcus; RHD, rheumatic heart disease; SAP, secondary antibiotic prophylaxis; TASH, Tikur Anbessa Specialized Hospital.

\section{Ethics Approval and Informed Consent}

Ethical clearance was obtained from the Ethical Review Board of School of Pharmacy, College of Health Sciences Addis Ababa University, Addis Ababa, Ethiopia. Then, permission was obtained from the hospital to conduct the study. Verbal consent was obtained from study participants before participating in the study. Information obtained from the collected data during the study was only handled by the research team.

\section{Data Sharing Statement}

All data used and/or analyzed during this study were included in this manuscript and are also available from the corresponding author on request.

\section{Acknowledgments}

The authors acknowledge TASH for allowing this research to be conducted. Furthermore, we would like to thank study participants, data collectors and nurses working in the cardiac clinic of the hospital for their time and voluntary facilitation for the data collection process. 


\section{Author Contributions}

All authors contributed to data analysis, drafting or revising the article, gave final approval of the version to be published, and agree to be accountable for all aspects of the work.

\section{Funding}

The authors did not receive funding for this study.

\section{Disclosure}

The authors declare that they have no competing interests.

\section{References}

1. Carapetis JR, Beaton A, Cunningham MW, et al. Acute rheumatic fever and rheumatic heart disease. Nat Rev Dis Primers. 2016;2:15084. doi:10.1038/nrdp.2015.84

2. Mendis S, Puska P, Norrving B. Global Atlas on Cardiovascular Disease Prevention and Control. Geneva: World Health Organization; 2011.

3. Seckeler MD, Hoke TRJC. The worldwide epidemiology of acute rheumatic fever and rheumatic heart disease. Clin Epidemiol. 2011;3:67-84. doi:10.2147/CLEP.S12977

4. De Dassel JL, Fittock MT, Wilks SC, et al. Adherence to secondary prophylaxis for rheumatic heart disease is underestimated by register data. PLoS One. 2017;12:e0178264. doi:10.1371/journal.pone.0178264

5. Cannon J, Roberts K, Milne C, et al. Rheumatic heart disease severity, progression and outcomes: a multi-state model. JAHA. 2017;6: e003498. doi:10.1161/JAHA.116.003498

6. Barik RJ. Secondary prophylaxis to control rheumatic heart disease in developing countries: put into a cage if can't be killed. Indian Heart J. 2018;70:907-910. doi:10.1016/j.ihj.2018.01.001

7. Gemechu T, Mahmoud H, Parry EH, Phillips DI, Yacoub MH. Community-based prevalence study of rheumatic heart disease in rural Ethiopia. Eur J Prev Cardiol. 2017;24:717-723. doi:10.1177/ 2047487316687104

8. Rémond MG, Coyle ME, Mills JE, et al. Approaches to improving adherence to secondary prophylaxis for rheumatic fever and rheumatic heart disease. Cardiol Rev. 2016;24:94-98. doi:10.1097/ CRD.0000000000000065

9. Ralph AP, De Dassel JL, Kirby A, et al. Improving delivery of secondary prophylaxis for rheumatic heart disease in a high-burden setting: outcome of a stepped-wedge, community, randomized trial. J Am Heart Assoc. 2018;7:e009308. doi:10.1161/JAHA.118.009308

10. Holland JV, Hardie K, de Dassel J, et al. Rheumatic heart disease prophylaxis in older patients: a register-based audit of adherence to guidelines. Open Forum Infect Dis. 2018;5:1-7.

11. de Dassel JL, de Klerk N, Carapetis JR, et al. How many doses make a difference? An analysis of secondary prevention of rheumatic fever and rheumatic heart disease. J Am Heart Assoc. 2018;7:e010223. doi:10.1161/JAHA.118.010223

12. Stewart T, McDonald R, Currie BJ, et al. Acute rheumatic fever: adherence to secondary prophylaxis and follow up of Indigenous patients in the Katherine region of the Northern Territory. Aust $J$ Rural Health. 2007;15:234-240. doi:10.1111/ajr.2007.15.issue-4

13. Musoke C, Mondo CK, Zhang W, et al. Benzathine penicillin adherence for secondary prophylaxis among patients affected with rheumatic heart disease attending Mulago Hospital. CJV Africa. 2013;24:124-129.
14. Gasse B, Baroux N, Rouchon B, et al. Determinants of poor adherence to secondary antibiotic prophylaxis for rheumatic fever recurrence on Lifou, New Caledonia: a retrospective cohort study. BMC Public Health. 2013;13:131. doi:10.1186/1471-2458-13-131

15. Thompson SB, Brown CH, Edwards AM, et al. Low adherence to secondary prophylaxis among clients diagnosed with rheumatic fever. JAMAICA Pathog Glob Health. 2014;108:229-234. doi:10.1179/ 2047773214Y.0000000146

16. Mohammed K, Demissie WR, Gare MB, et al. Adherence of rheumatic heart disease patients to secondary prophylaxis and main reasons for poor adherence at Jimma Medical Center. EJCM. 2019;7:22-27. doi:10.32596/ejcm

17. Günther G, Asmera J, Parry E. Death from rheumatic heart disease in rural Ethiopia. Lancet. 2006;367:391. doi:10.1016/S0140-6736(06)68128-2

18. Engel ME, Haileamlak A, Zühlke L, et al. Prevalence of rheumatic heart disease in 4720 asymptomatic scholars from South Africa and Ethiopia. BMJ Heart. 2015;101:1389-1394. doi:10.1136/heartjnl-2015-307444

19. Mulatu H, Woldemichael MA. Prevalence of rheumatic heart disease among primary school students in Mid-Eastern Ethiopia. Biol Syst Open Acces. 2015;5:1-4. doi:10.4172/2329-6577.1000149

20. Grayson S, Horsburgh M, Lennon D. An Auckland regional audit of the nurse-led rheumatic fever secondary prophylaxis programme. N Z Med J. 2006;113:U2255.

21. Sial JA, Farman MT, Batra MK, Karim MJ. Adherence to secondary prophylaxis of rheumatic fever in patients with rheumatic heart disease in rural areas. Pak Heart J. 2018;51:243-247.

22. Balbaa A, ElGuindy A, Pericak D, et al. An evaluation of secondary prophylaxis for rheumatic heart disease in rural Egypt. GCSP. 2015;40:1-8.

23. Engelman D, Ah Kee M, Mataika R, et al. Secondary prevention for screening detected rheumatic heart disease: opportunities to improve adherence. Trans $R$ Soc Trop Med Hyg. 2017;111:154-162. doi: $10.1093 / \operatorname{trstmh} / \operatorname{trx} 035$

24. Saxena A, Mehta A, Ramakrishnan S. Adherence to benzathine penicillin in children with rheumatic fever/rheumatic heart disease: results from an Indian pediatric RHD registry. JACC. 2015;65: A2019. doi:10.1016/S0735-1097(15)62019-8

25. Huck DM, Nalubwama $H$, Longenecker CT, et al. A qualitative examination of secondary prophylaxis in rheumatic heart disease: factors influencing adherence to secondary prophylaxis in Uganda. Glob Heart. 2015;10:63-69. doi:10.1016/j.gheart.2014.10.001

26. Tullu MS, Gandhi A, Ghildiyal RG. Benzathine penicillin prophylaxis in children with rheumatic fever (RF)/rheumatic heart disease (RHD): a study of compliance. Al Ameen J Med Sci. 2010;3:140-145.

27. Culliford-Semmens N, Tilton E, Webb R, et al. Adequate adherence to benzathine penicillin secondary prophylaxis following the diagnosis of rheumatic heart disease by echocardiographic screening. $N Z$ Med J. 2017;130:50.

28. Oetzel JG, Lao C, Morley M, et al. Efficacy of an incentive intervention on secondary prophylaxis for young people with rheumatic fever: a multiple baseline study. BMC Public Health. 2019;19:385. doi:10.1186/s12889-019-6695-3

29. Farzana K, Faruque MO, Zareen S, et al. Factors affecting therapeutic compliance among the patients with rheumatic heart disease in Bangladesh. Cardiovasc. 2018;10:180-185. doi:10.3329/cardio.v10i2.36289

30. Engelman D, Mataika RL, Kado JH, et al. Adherence to secondary antibiotic prophylaxis for patients with rheumatic heart disease diagnosed through screening in Fiji. Trop Med Int Health. 2016;21:1583-1591. doi:10.1111/tmi.12796

31. Wyber R, Boyd BJ, Colquhoun S, et al. Preliminary consultation on preferred product characteristics of benzathine penicillin $\mathrm{G}$ for secondary prophylaxis of rheumatic fever. Drug DelivTransl Res. 2016;6:572-578. 


\section{Publish your work in this journal}

Patient Preference and Adherence is an international, peer-reviewed, open access journal that focusing on the growing importance of patient preference and adherence throughout the therapeutic continuum. Patient satisfaction, acceptability, quality of life, compliance, persistence and their role in developing new therapeutic modalities and compounds to optimize clinical outcomes for existing disease

states are major areas of interest for the journal. This journal has been accepted for indexing on PubMed Central. The manuscript management system is completely online and includes a very quick and fair peer-review system, which is all easy to use. Visit http:// www.dovepress.com/testimonials.php to read real quotes from published authors.

Submit your manuscript here: https://www.dovepress.com/patient-preference-and-adherence-journal 